\title{
Alleviating Urban Traffic Congestion: Case of Gaborone City
}

\author{
Shakerod Munuhwa* Ephraim Govere Bonang Mojewa Abbas Lusenge \\ Business Management Department, BAISAGO University, Bag 149, Gaborone, Botswana. \\ *E-mail: shakerodm@gmail.com
}

\begin{abstract}
Cities in the developing world have not been spared from the congestion problems due to economic growth and subsequent increase in vehicle ownership by both private and public owners. Traffic congestion is a major challenge in Gaborone, especially in the Western by pass road of the city resulting in massive delays, a decrease in productivity, an increase in environmental pollution, and an increase in travel time. The objective of this paper is to analyse urban transportation congestion, identify causes and proffer solutions through engaging road user perceptions, transport planning authorities and transport policy makers in Botswana. The study employed an exploratory design to sample 208 respondents through the administration of questionnaires. Quantitative data were used and analysed using SPSS v 21. The study revealed that there is massive influx of motor vehicles in the city, inadequate urban infrastructure, poor infrastructural planning, poor or no urban transport policy framework, and Road Traffic Incidents were the main causes of traffic congestion. The effects of traffic congestion are higher transport costs, massive delays, pollution, decreased productivity and stress to motorists as a result of longer travelling time. The study recommends improvement of road infrastructure especially intersections with traffic circles, implementation of mass transit system in transporting public within the city, public education on effects of congestion, implementation of smart urban transportation, mobility technologies (transport intelligence systems) and implementation of non-motorised mobility.
\end{abstract}

Keywords: congestion, Gaborone, urban transport, Botswana, mass transit, Main Mall, central business district.

DOI: $10.7176 / \mathrm{JESD} / 11-8-06$

Publication date: April $30^{\text {th }} 2020$

\section{Introduction}

Traffic congestion refers to the way the movement of vehicles is delayed by one another because of limited road capacity (Rahane \& Saharkar, 2014). In simpler terms, road congestion occurs when the demand for traffic nears or surpasses the capacity of the road network (Raheem et al., 2015). Traffic congestion is one of the worldwide urban problems, which can lengthen journey time, increase energy consumption, reduce industrial and commercial productivity, aggravate environmental pollution and result in traffic accident, (Currie \& Walker ,2011). Urban Traffic congestion has been a problem especially for most big cities in both developed and developing nations and it is predicted to get worse in the future (Kiunsi, 2013). According to (Texas Transportation Institute, 2011), traffic congestion in the US has increased substantially over the last 25 years. The Brazilian city of Sao Paulo is known to have experienced the world's worst traffic jams, where people are stuck for two to three hours every day in traffic jams (Mahendra, 2009). Such situation has obvious implication on productivity and the socio-economic development at large resulting in delays, fuel wastage and money loss (Texas Transportation Institute, 2011 Mobility report).

The urbanisation of developing world cities resulted in an influx of unmanageable urban planning and development problems such as the rapid increase in vehicles as well as the inefficiency of vehicles contributing to congestion (United Nations Environmental Programme 2014). Existing road and traffic management infrastructure, however, could not substantially accommodate the sudden surge in vehicle ownership and traffic congestion. Although traffic congestion is experienced in both developed and developing world countries, studies confirm that it is more prevalent in the developing world (World Bank, 2017). A study by the World Bank (2017) alluded to there being a growth in demand for urban transportation operations in Sub-Saharan African countries to manage the rapid growth of motorised transportation and decrease in accessibility of Non-Motorised Transportation. Lack of accessibility of Non-Motorised transportation and the rapid growth of motorised transportation pose challenges to developing countries (Mahendra et al. 2016). Over the years, modal shift from private vehicle travel to public transportation and Non-Motorised transportation has been used to promote transportation sustainability; to save costs, reduce number of vehicles on the roads, reduced carbon emissions, reduced travel time and clear parking spaces in city centres (Batty, Palacin, and González-gil 2015; Conti 2018; Salvucci et al. 2018). Modal shift has worked in some cities with more efficient public transportation systems along with strict rules and policies, discouraging the use of private vehicles. There has been a surge in private vehicle ownership in Gaborone over the past two decades, leading to increased traffic congestion levels and longer trip durations. 


\section{Background of the Study}

Botswana has over the years registered a steady economic growth and has seen a tremendous development in the transport sector, particularly road transport resulting in significant traffic growth as shown by the national fleet which increased from 33,413 in 2008 to 55,341 new vehicles by 2018 representing a $65.6 \%$ growth, increasing the congestion levels in the process (see Figure 2.1). Note has been taken that for vehicles registered in Q2 and Q3 of 2019 an average of $65.6 \%$ were registered in Gaborone meaning that the bigger number of Botswana vehicles exist in Gaborone. (Dept. of Road Transport \& Safety, Botswana, 2019). A major contribution to this growth has largely been due to relatively affordable cars imported from Asia, indicated by 78\% of all vehicles registered in Q3 2019 being imported from Japan.(Statistics Botswana, 2019). Congestion for Gaborone is further exacerbated by the growth of passenger and van type of vehicles which are private and single occupancy vehicles, these on average account for $81 \%$ of the total vehicles registered between 2008 and 2018(see Table 2.1) (Dept. of Road Transport \& Safety, Botswana, 2019).

The population of locally registered vehicles on the country's roads rose to 584,000 by the end of June 2019, more than double the number from 10 years ago. At that level, the country has about 254 vehicles per 1,000 people in the country, a statistic that puts Botswana amongst the world's highest in terms of vehicle density, (Mmegionline 01 November 2019). Considering the limitations of Botswana's road infrastructure, such levels of growth are somewhat ill-disposed, most especially in major urban centres like Gaborone. In this regard, measures to control traffic congestion in the city are urgently called for.

Figure 2.1: Vehicle first registrations in Botswana

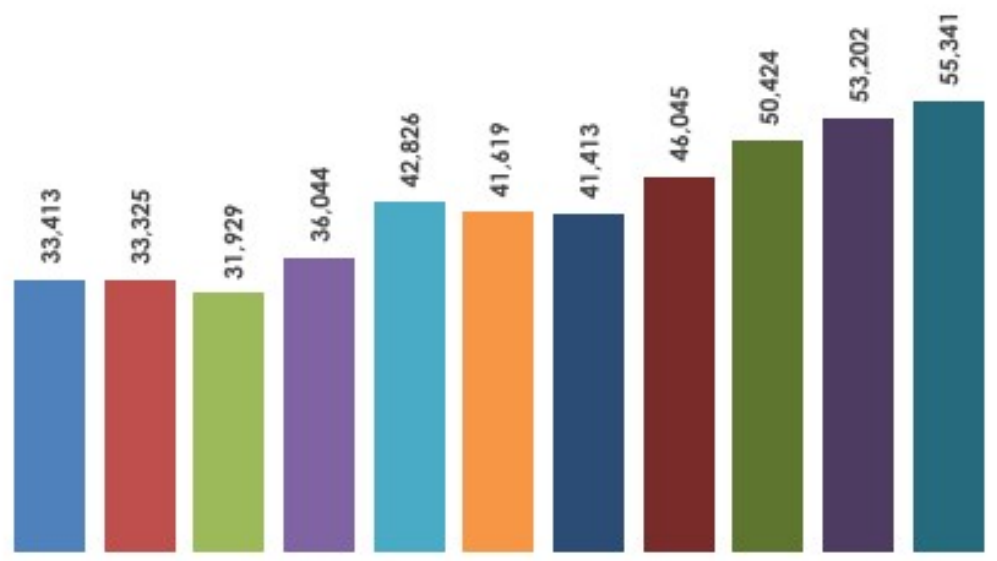

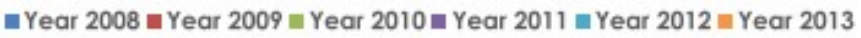

aYear 2014 a Year 2015 a Year 2016 a Year 2017 a Year 2018

Source: (Statistics Botswana Q3 , 2019)

Table 2.1: Passenger vehicles and Vans registered

\begin{tabular}{|c|r|r|r|r|c|}
\hline $\begin{array}{c}\text { Year of first } \\
\text { registration }\end{array}$ & Pasenger cars & \multicolumn{1}{c|}{ Vans } & $\begin{array}{c}\text { Total of Passenger } \\
\text { cars and Vans }\end{array}$ & $\begin{array}{c}\text { \% of passenger cars and } \\
\text { Total vehicles } \\
\text { registered }\end{array}$ & $\begin{array}{c}\text { vans over total vehicles } \\
\text { registered }\end{array}$ \\
\hline 2008 & 20,037 & 5,912 & 25,949 & 33,413 & $78 \%$ \\
\hline 2009 & 19,354 & 5,831 & 25,185 & 33,325 & $76 \%$ \\
\hline 2010 & 20,972 & 4,040 & 25,012 & 31,929 & $78 \%$ \\
\hline 2011 & 25,204 & 3,426 & 28,630 & 36,044 & $79 \%$ \\
\hline 2012 & 31,471 & 4,160 & 35,631 & 42,826 & $83 \%$ \\
\hline 2013 & 31,122 & 3,661 & 34,783 & 41,619 & $84 \%$ \\
\hline 2014 & 29,319 & 4,963 & 34,282 & 41,413 & $83 \%$ \\
\hline 2015 & 34,372 & 4,380 & 38,752 & 46,045 & $84 \%$ \\
\hline 2016 & 37,562 & 4,654 & 42,216 & 50,424 & $84 \%$ \\
\hline 2017 & 40,847 & 3,667 & 44,514 & 53,202 & $84 \%$ \\
\hline 2018 & 42,529 & 3,857 & 46,386 & 55,341 & $84 \%$ \\
\hline Totals & 332,789 & 48,551 & 381,340 & 465,581 & $81 \%$ \\
\hline
\end{tabular}

Source: (Statistics Botswana Q3, 2019)

The daily traffic jams on Botswana's urban roads, Gaborone in particular, are common to all car users. 
Gridlocks on the Wellie Seboni Road which intersects with Nelson Mandela Drive in the east and connects to the so-called Btv traffic circle in the west, right through part of Mogoditshane; Gaborone/Molepolole road and the Gaborone/Kanye road at both morning and afternoon rush hours, are typical examples of congested roads,(Ranko and Bolaane,2011). Scholars have proposed congestion pricing as a way of effecting modal shift to public transportation. Modal shift is often promoted as a congestion reduction measure. Modal shift consists of a transfer of mobility demand across modes of transport, as a result of changes in modal choice (Salvucci et al., 2018). Efforts to encourage modal shift focus on improving the quality and attractiveness of public transportation as well as discouraging or preventing car usage, (Batty et.al, 2015), the pull and push method, which has mostly been unachievable due to challenges such as cultural, technological and regulatory factors, lack of information and poor decision making by policymakers. Often public transportation systems are considered unreliable, unsafe and inconvenient, resulting in people who have access to private vehicles being less interested in the use of public transportation. Private vehicles are used for flexibility, personal space and convenience (Batty et.al, 2015).

Figure 2.2: Gaborone City (Congested area road map)

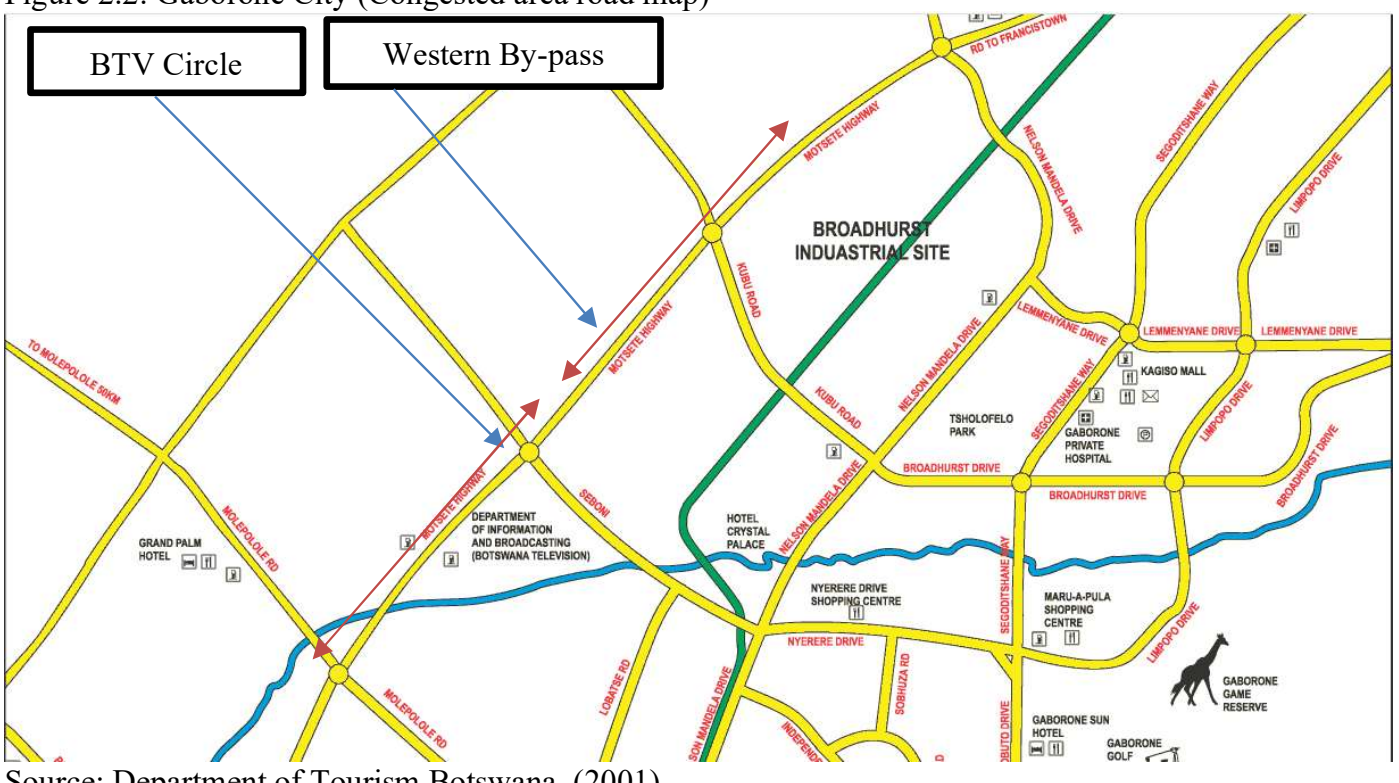

Source: Department of Tourism Botswana, (2001)

The increase in the number of private vehicles has been largely blamed for the increased congestion levels. People use private vehicles over public transportation in order to avoid the stereotypical displeasing issues of public transportation. Even though studies alluded to public transportation as being safer than private vehicle travel, having higher fatality rates compared to public transport, (Litman 2013)

\section{Statement of The Problem}

Most of the cities are undergoing multifaceted problem because of rapid urbanization. Traffic congestion is one of the intolerable problems of urban area emerging due to sudden increment in the private transport, affecting urban society, economy. Road traffic congestion poses a serious challenge for all large and growing cities. Congestion prevents the movements of traffic, leading to the intolerable increase journey time,(Maji, 2017).Gaborone is currently experiencing intolerable traffic congestion in major roads especially those with traffic circle intersections. This type of congestion happens at the crucial time in the morning and late afternoon. Some of the roads and intersections are congested the whole day resulting in a lot of productive time being wasted in roads. A lot of urgent and emergency services are not easily moved from one point to the other within the city due to high congestion, this is exacerbated by lack of emergency lanes in Gaborone roads. This paper therefore seeks to explore the causes of congestion in Gaborone city and proffer solutions which are appropriate to reduce this type of congestion.

The following research questions guided this study:

1. What are the causes of traffic congestion in Gaborone city?

2. What are the effects of traffic congestion in Gaborone city?

3. What are the possible measures needed to reduce traffic congestion in Gaborone city?

Research Objectives:

1. To identify the causes of traffic congestion in Gaborone city.

2. To establish the effects of traffic congestion to Gaborone city. 
3. To pinpoint possible measures needed to reduce traffic congestion in Gaborone city.

Studies like this will help improve on managing traffic congestion in the biggest city of Botswana and as such influence policy, which can be replicated in other cities and towns across the country. The findings of this study are of importance to urban transport planners, policy makers, drivers, pedestrians, and shoppers in the city of Gaborone. It will help elicit the various causes and effects of traffic congestion in Gaborone. The study will also provide information on the measures to manage traffic congestion in the Gaborone. This paper anticipates expanding the existing knowledge about tackling traffic congestion in Botswana as a developing country. Furthermore, results of this study can be used to manage existing problems of traffic congestion in cities of other developing countries with similar characteristics.

The paper is divided into seven sections. Section one is the introduction and background of the study. Following section one is the literature review showing the causes and effects of traffic congestion and how it is being managed. Section three presents the study area with section four containing the research methodology. Section five contains the results with section six presenting the discussion. Section seven concludes with the conclusion and policy implications.

\section{Literature Review}

\subsection{Traffic congestion as a concept}

There is no single definition of traffic congestion as it is both a physical and a relative phenomenon (Rahane \& Saharkar, 2014). As a physical phenomenon, it is defined as a situation where demand for road space exceeds supply and is reflected by slower speed, longer trip times and increased motor vehicular queuing (Downie, 2008). It is a relative phenomenon when there is a difference between road performance and road user's expectations (Downie, 2008; Kiunsi, 2013).

Traffic congestion can be perceived as an unavoidable consequence of scarce transport facilities such as road space, parking area, road signals and effective traffic management (Blanco et al., 2009). Urban congestion mainly concerns two domains of circulation, passengers, and freight, which share the same infrastructure. Thus, traffic congestion condition on road networks occurs as a result of excessive use of road infrastructure beyond capacity, and slower speeds, longer trip hours and increased vehicular queuing characterize it. Any city that is economically active and vibrant will rarely be free from traffic congestion (Yildirim, 2001). Ndakhona, (2020), elaborated that ttraffic congestion in Gaborone city is undeniably high during peak hours and experienced at by most of the road users travelling regularly within the city. The state of congestion is likely to increase over the years as a result of the increasing number of people eligible to purchase a vehicle and the projected growth of car registrations. Long delay times are highly and further influenced by the limited road network of the city.

\subsection{Types of traffic congestion}

Two types of traffic congestion were singled out, recurrent congestion, and nonrecurring congestion. Recurrent congestion generally occurs at the same place, at the same time every day. This is generally the consequence of factors that act regularly or periodically on the transportation system such as daily commuting or weekend trips, (Victoria Transport Policy Institute, 2009). Recurrent congestion is predictable and typically occurs during peak hours. It displays a large degree of randomness in terms of duration and severity. On-Recurrent Congestion is the effect of unexpected or unplanned large events, example; road works, accidents, special events, and other related events or activities that affect transportation system more or less randomly and as such, cannot be easily predicted. The study gives more emphasis on recurrent type of congestion.

\subsection{Causes of traffic congestion}

There are a number of specific circumstances, which cause or aggravate congestion: rapid increase in urban population, economic growth, increase employment opportunities, increase in number of cars and number of people using cars, low capacity of transport infrastructure, road layout, underinvestment in road infrastructure, poor traffic management, shortage of street parking, signal and equipment failure, non-adherence to traffic regulations, poor urban planning or poor urban development control, the rapid expansion of city boundaries, poor public transport, increased use of private cars, car accidents, special events gatherings, road works, and bad weather (Andoh, 2014).

The European Conference of Ministers of Transport (ECMT) (2007) alluded that traffic congestion is caused by a number of factors such as; poor pavements, too many vehicles and motorcycle, land use patterns, employment patterns, income levels, car ownership trend, infrastructure investment, regional economic dynamics, tourism, poor land use integration among other factors.

4.3.1. Causes of traffic congestion in developing countries

The situation has worsened for developing countries due to the following reasons: unplanned cities, poor discipline, alternate traffic means, archaic management, and improper lane management (Mbara ,2015). Unplanned cities: roads are narrow and poorly built. As cities grow in an ad hoc manner, no provision is made 
towards scaling road capacities, eventually resulting in several bottleneck roads, which remain congested for extended periods of time. Furthermore, many developing countries have witnessed an explosive growth in their vehicular population resulting in a failure of conventional traffic management strategies.

Poor discipline: drivers often are not trained enough to follow lane discipline. The impact of poor lane discipline, especially at traffic junctions, deteriorates the already overcrowded junction situation. Furthermore, drivers frequently jump red lights and block the intersection, causing further traffic congestion. These problems are compounded by the fact that traffic law enforcement is poor, thereby providing no incentive for drivers to follow the rules.

Alternate traffic means: countries with fast-growing economies have witnessed a surge in the number of vehicles across major cities. These cities seldom have efficient mass transit systems, forcing people to operate private vehicles. This problem is compounded by the social stigma, where people view operating a private vehicle as a sign of prosperity, while public transport is viewed as being used by the lower echelons of society, (Shamsher \& Abdullah, 2015)

Archaic management: traffic junctions are often unmanned, thereby allowing drivers to drive in a chaotic manner. Even if a junction is controlled by a police officer or a traffic light, the traffic junctions are largely independent of any traffic management strategy, only optimizing the respective junction traffic flow, in the direction of maximum traffic build up. Furthermore, these approaches enhance traffic mismanagement in already congested roads, accelerating congestion collapse.

Improper lane management: lane management is an important fact in managing the traffic. Many types of vehicles try to overtake other vehicles even in the single undivided road. This is the main reason that the city roads are unequipped with the lane dividers, which divide the lane into incoming and outgoing traffic.

4.3.2. Causes of traffic congestion in Gaborone

According to (Mensah et al, 2014), the causes of traffic congestion in any location can best be grouped into four categories called horizontal factors, vertical factors, traffic control devices, and loading and dropping of passengers along the road.

4.3.2.1 Horizontal causes of urban traffic congestion

These factors include poor road network: Transportation engineers have long studied and addressed the physical capacity of roadways, the maximum amount of traffic capable of being handled by a given highway section. Capacity is determined by a number of factors: the number and width of lanes and shoulders of roads; merge areas at interchanges; and roadway alignment (grades and curves). Bad roads cause congestion that results into accidents, it's not all accidents of automobiles that are a result of driver's error but sometimes roads conditions are to blame (Zhang ,2011). Pavement edge drop-offs, bad curves, potholes and poor slope construction, cause serious injuries and even death. Pavement edge drop-offs seem to cause serious accidents. When a car's tire drops off one of these edges bounce can occur, causing the driver to over-react and oftentimes lose control. Most of Gaborone's roads are designed with traffic circles at major intersections (as seen in the Western by pass road with four traffic circles over a distance of $12.7 \mathrm{~km}$ from Airport junction mall to Game City Mall) resulting in long hours of traffic congestion.

4.3.2.2 Traffic control devices traffic control congestion.

Intermittent disruption of traffic flow by control devices such as traffic lights not working railroad grade crossings and poorly timed signals also contribute to congestion and travel time variability. This is experienced in Gaborone in a number of busy roads resulting in massive traffic congestion.

\subsection{Effects of traffic congestion}

The effects of traffic congestion can be categorized into four main groups of environmental, economic, health and social (Mahmud et al., 2012). The nature, extent, and severity of the effects differ from one city to another depending among other things the city size, road capacity and road layout, spatial distribution of land use, modes of public and private transport systems and travel patterns (Kiunsi, 2013).

(Mahmud et al, 2012) expounded that traffic congestion increases travel cost, he mentioned various costs caused by traffic congestion, traffic slows down speed which is a visible cost and when people forgo their trips because of fear for congestion then it becomes a hidden cost of congestion and when traffic congestion make people not to believe in their cities they miss finding better jobs, and sharing better amenities

Despite the growing number of hybrid vehicles on the road, cars stopped in traffic still produce a large volume of harmful carbon emissions. Besides contributing to global warming, these emissions can cause more short-term and localized problems, such as smog and increased respiratory problems in a community due to poor air quality. Commuters who are exposed to air pollution, like those riding in non-air conditioned vehicles, double their health risk. Aside from stress, they are also exposed to pollutants that can affect the lungs.

The economic impacts are increasing in fuel consumption, which leads to higher transportation costs, wastage of working time and delay in service delivery which mainly reduces overall urban productivity. Borrowed from the Herald 8 June 2018, South Africa loses R1.5 billion annually as a result of urban traffic congestion while 
Egypt's capital Cairo loses \$8billion annually which is about $4 \%$ of that country's Gross Domestic Product.

Information regarding the actual cost of traffic congestion in Gaborone is conspicuously scanty, but it cannot be denied that traffic congestion affects all of us since transport externalities affect owners and non-car owners alike and the penalty paid by the nation is recurrently multiplying. Some of the adverse effects of traffic congestion are: increases in the average travel or commute time for both private motorists and consumers of public transport services; delays which result in late arrival for work and meetings (resulting in unfavorable effects such as, disciplinary actions, loss of business etc.), road traffic accidents, noise pollution, fuel wastage due to increased idling and; stress and frustration which may culminate in reduced health and cases of road rage (FHWA, 2006).

The impact on Botswana is obviously colossal if thriving economies such as South Africa and Egypt can feel it to such levels. Health impacts, which primarily occur due to extended exposure to polluted air and unnecessarily long periods spent on roads, are mental stress, tiredness, and headache. Social impacts include a reduction in quality of life as reflected by a reduction in personal incomes due to increased transportation costs and less productivity, loss of time that could have otherwise been spent on social activities (Mbara, 2015). Drivers who become impatient may be more likely to drive aggressively or dangerously.

\subsection{Managing traffic congestion}

Traffic congestion in urban areas cannot be completely eliminated but can only be minimized to an acceptable level and its approach is multi-faceted. Rodrigue, Comtois, and Slack (2009) outline some measures that could help deal with the congestion menace-traffic signal synchronization, incident management, congestion pricing and the use of public transit as possible effective strategies available in dealing with congestion situation, although not without their associated challenges.

\subsubsection{Mass Transit Transport system}

The mass transport system is a reasonable suggestion because the present public transport system is characterised by small vehicles and the operations are fragmented and inefficient as they are run by individuals. Secondly, mass transit vehicles carry a far higher number of passengers, making them an efficient user of road space, ultimately decongesting the city. Thirdly, due to their sizes and ability to carry people in mass, the cost per passenger kilometer is lower, making them affordable to users. Fourthly, as mass transit systems carry more efficient engines, they can save fuel better than small vehicles. Finally, their impact (negative effects) on the external environment is lower compared to small vehicles. Mass transit vehicles therefore provide solutions to the economic, social, energy and environmental challenges in the city. Gaborone City Council has in the past conducted studies to map the way for developing public transport. One such study is the 1995 City Traffic Planning and Management (Bashingi et al. 2020) and the Final Draft of which recommended at page 18, that "25-seater vehicles should be introduced in new areas of Gaborone which had no existing transport services." This proposal, which could have further reduced the number of vehicles on the road, has not yet been implemented primarily because of lack of political support and resistance by the baseline or existing transport operators, (Bashingi et al.,2020)

4.5.2. Non-Motorised transport

Traffic congestion erodes the general level of safety for pedestrians and has the effect of stunting walkability. In Gaborone, there is a general inadequacy of traffic calming measures near schools, and 'home zones'. This discourages many people from walking due to fear to be involved in vehicular/pedestrian accidents. Presently, cycling and walking represent only $0.20 \%$ and $30 \%$ of trips in Gaborone respectively (Greater Gaborone Multimodal Transport Study Report, 2008). In addition, it is apparent that cycle paths and pedestrian sidewalks in Gaborone are inadequate in various respects and to some extent, sporadic. A study by the World Bank (2017) alluded to there being a growth in demand for urban transportation operations in Sub-Saharan African countries to manage the rapid growth of motorised transportation and decrease in accessibility of Non-Motorised Transportation. Lack of accessibility of Non-Motorised transportation and the rapid growth of motorised transportation pose challenges to developing countries (Mahendra et al. 2016). Over the years, modal shift from private vehicle travel to public transportation and Non-Motorised transportation has been used to promote transportation sustainability; to save costs, reduce number of vehicles on the roads, reduced carbon emissions, reduced travel time and clear parking spaces in city centres (Batty, Palacin, and González-gil 2015; Conti 2018; Salvucci et al. 2018). Modal shift has worked in some cities with more efficient public transportation systems along with strict rules and policies, discouraging the use of private vehicles. There has been a surge in private vehicle ownership in Gaborone over the past two decades, leading to increased traffic congestion levels and longer trip durations.

4.5.4. Improvement in road infrastructure planning and construction

Congestion can be reduced by either increasing road capacity (supply) or by reducing traffic (demand). Road capacity can be increased in a number of ways such as adding more capacity over the whole of a route, creating new routes, and improvements in traffic management. Reduction of demand can include, parking restriction, park, and ride, congestion pricing, road space rationing, incentives to use public transport and introduction of carpooling (Zhang, 2011). Improvements of roads through interchanges should follow similar successful projects in 
Francistown in 2016 (see Figure 4.1) and the Boatle interchange in May 2019. These infrastructure development projects have been widely received by motorists and urgent need is advocated for to follow suite in Gaborone as a big measure to reduce traffic congestion. Note has been taken also that most roads in Gaborone are not user friendly as they lack immediate turning points, this will make motorists travel unnecessarily into some areas contributing to congestion when they would have turned back. Roads should be re-designed to allow motorists many options to turn sideways or back. Roads should be designed in such a way that more than one road can be used to reach a major economic point like the Malls and residential areas, this will go a long way in reducing traffic congestion as motorist share the existing road options.

Figure 4 .1: Francistown Interchange (Botswana)

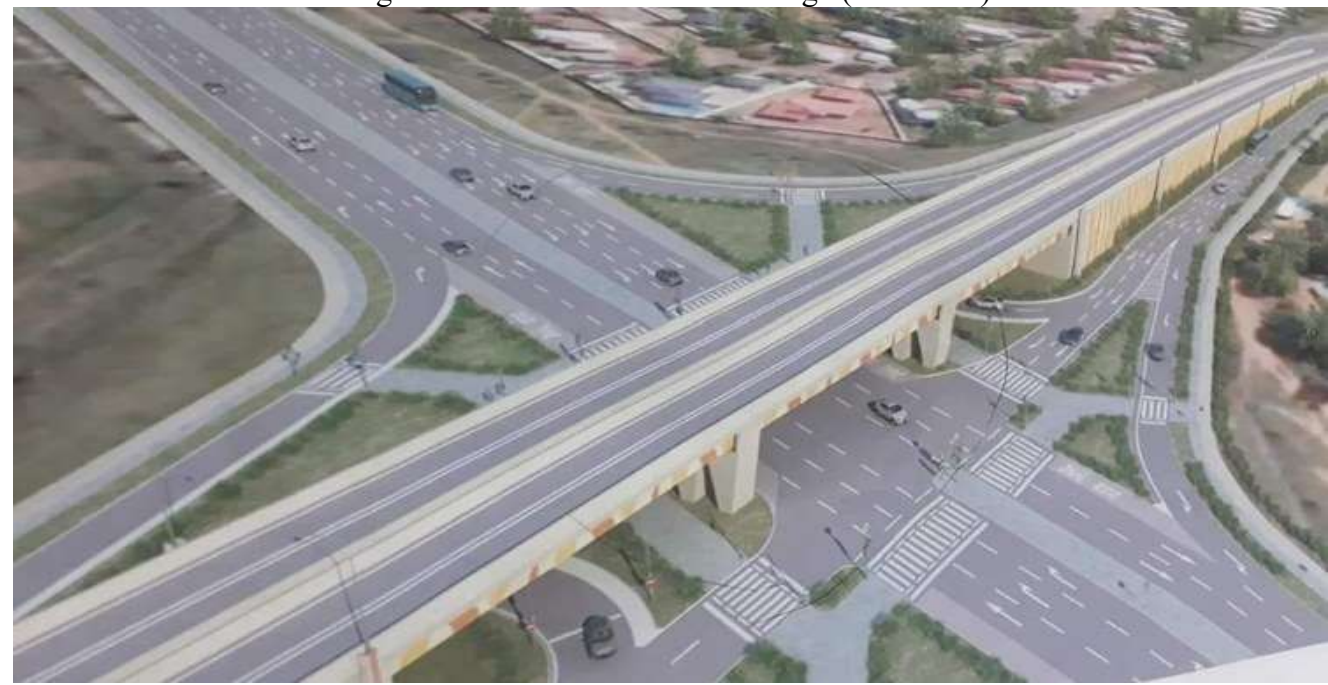

Source: Field Survey 2020

4.5.5 Electronic Road Pricing (ERP)

Electronic Road Pricing (ERP) is another congestion counter-measure worth pioneering to control entry into the city centre during traffic peak times. Road pricing is a rubric for all mechanisms of collecting a levy from motorists for using a particular restricted segment of the road in a bid to reduce traffic congestion. Opportunities abound for the introduction of ERP in both the CBD and the Gaborone main Mall, (Ranko and Bolaane, 2011)

4.5.6 Paid parking

Free parking serves as an incentive for motorists to use their cars for short trips to the City and major urban places infested with high volumes of traffic. This culminates in congested streets in busy portions of Gaborone such as the main Mall being de-congested. Presently, parking is free in all areas of the city for use by the public except where some organizations have provided restricted parking for the sole use by their employees. Introducing paid parking, most especially in the Central Business District, is not necessarily a wild card and can reduce road traffic congestion in some parts of the city. Aside from generating income for the city, it can ensure that only people with imperative errands to perform in such areas gain access, thereby decreasing traffic congestion, (Ranko and Bolaane, 2011).

\section{Study area}

The city of Gaborone is the capital city of Botswana, a landlocked Southern Africa country sharing its borders with Zimbabwe, Zambia Angola, South Africa and Namibia. Botswana has a population of 2.3million of which of 231592 , which is projected to grow to 292656 by 2023 is from the capital city of Gaborone (Statistics Botswana, 2019). The annual vehicle registration growth rate in Botswana has been increasing by $7.4 \%$ since 2007 , largely due to import cars (Statistics Botswana, 2016). Traffic control measures in the city are in the form of traffic circles and traffic lights on the city's busiest roads; four roundabouts along the Western Bypass and two along Notwane Road which leads to the city's largest hospital and the country's largest university. Visible pedestrian infrastructure available in the city is pedestrian crossings and walkovers in busy sections of the city and at intersections. There is no provision for sidewalks, or infrastructure allowing for pedestrians and cyclists to walk or cycle comfortably and conveniently from residential areas to the city centre, commercial and industrial areas within the city, (Bashingi et al.,2020).

\section{Methodology}

6.1 Research Design

The exploratory research design was used for this study, which is not intended to provide conclusive evidence but 
to help in better understanding a phenomenon. Exploratory research tends to tackle new problems on which little or no previous research has been done (Sarantakos, 2006). In line with the present research, the paper adopts both qualitative and quantitative research methods. As part of the quantitative research, a questionnaires was designed and distributed to the target population. The questionnaire was the main tool for data collection, and it comprised of three sections on the impacts of traffic congestion. The questionnaire items were constructed and adapted from the existing intensive literature review. In this paper, the degree to which respondents agreed that traffic congestion affected the society, economy and environment was measured on a five-point Likert Scale. Data collected through the quantitative survey were coded and recorded using the SPSS software for inferential analysis. Finally, a statistical test was carried out to analyse the difference between the population mean and the sample mean of the impacts of traffic congestion.

\subsection{Sampling Plan}

The target population comprises of people travelling within Gaborone city, and those who were conveniently available to partake in the study. The sampling procedures were certainly aimed at satisfying the main demographic variables and the targeted sample frame consists of all relevant types and the right mix of individuals to ensure that it reflects and represents the whole population. In the process of data collection, structured questionnaires were mainly used as research instrument for this paper, and these were distributed to the respondents on a face-toface basis, as well as via social media, e-mail, and in offices through friends and relatives.

\section{Empirical Findings}

Part A: Demographic Profile of Respondents

Table 7.1: Demographic Profile of Respondents

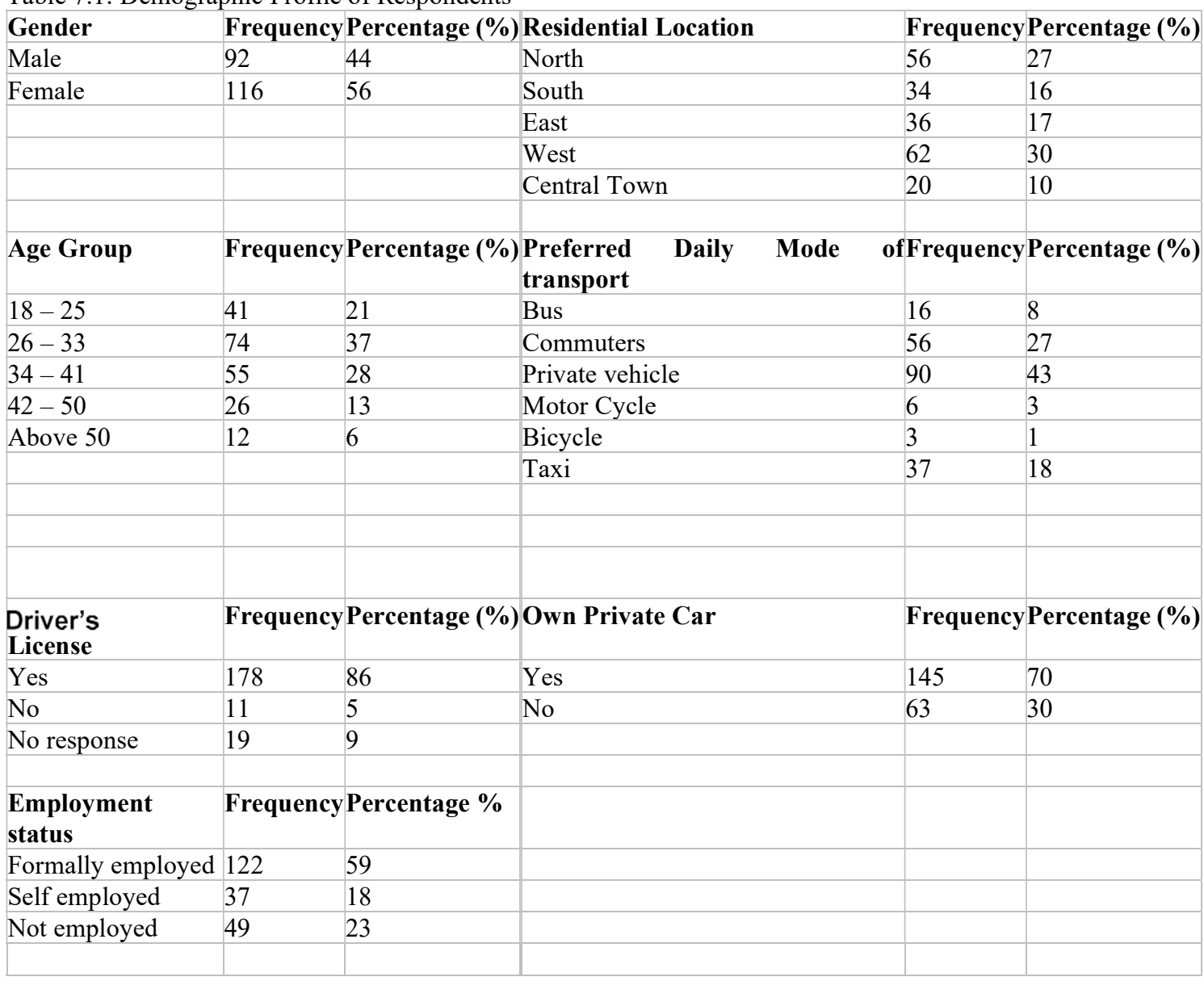

$\mathrm{n}=208$

Table 7.1 demonstrates the profile of respondents, where most respondents, being working people (formally and self employed), represent $77 \%$ of the sample, while the remaining $23 \%$ represent the non-working people, consisting mainly of students and a few adults. Out of the $77 \% \%, 18 \%$ of respondents are self employed.Demographic distribution of respondents $44 \%$ male and $56 \%$ femaled Most of the respondents belong 
to the age group of 26 - 33 years, representing $37 \%$ of the sample. Many respondents are from the western region of the town surbubs like G-west,Gabane and Mogoditshane etc , comprising (30\%) and the northern surbubs, comprising (27\%), surbubs like Oodi, Gnorth, Phakalane etc . $70 \%$ of the respondents highlighted that they private own cars (SOV). From the survey $43 \%$ of the responses indicated that they prefer using private vehicles when doing their daily movements within and outside the city, amongst these $43 \%, 48 \%$ of them further indicated that they prefer private and own vehicles for convinience as they do school runs 5 days a week. (27\%) of the respondents prefered using commuter omnibuses when doing daily runs withing and outside Gaborone. The figures show that mass transport is not prefered compared to Single occupancy vehicles (SOV).

Part B: Empirical Findings

Table 7.2: Mean Analysis - Causes of Traffic Congestion

\begin{tabular}{|c|c|c|}
\hline Variable being analysed & $\mathrm{N}$ & Mean \\
\hline Economic Growth and Development & 208 & 2.34 \\
\hline Excessive no. of Vehicles especially private SOV & 208 & 1.82 \\
\hline Population Growth & 208 & 2.41 \\
\hline Inefficient Public Transport Services & 208 & 2.35 \\
\hline Unforeseen Circumstances & 208 & 2.54 \\
\hline Poor Road Network and transport planning & 208 & 1.39 \\
\hline Job Centralisation & 208 & 2.37 \\
\hline Lack of Workplace Flexibility & 208 & 2.22 \\
\hline In adequate parking facilities & 208 & 2.49 \\
\hline
\end{tabular}

Statements on causes of traffic congestion in the questionnaire were based on a Likert Scale, whereby a mean value of 1 meant that respondents strongly agreed, while a mean of 5 meant that the respondents strongly disagreed with the statements. As indicated in Table 3, for a sample size of 208, the mean values of 2.34,2.41,2.35,2.54, 2.37,2.22,2.49, for Economic growth and development and growth, Population growth, Inefficient public transport, Unforeseen circumstances, Job centralisation, Lack of work place flexibility and Inadequate parking facilities respectively, Indicate that respondents on average partly agree that traffic congestion is partly a result of these factors. Also, by looking at the mean values of 1.82 and 1.39 for Excessive number of private vehicles and Poor road networking and transport planning respectively, it can be concluded that respondents, on average strongly agree that these two factors are the main causes of traffic congestion in the city of Gaborone.

Table 7.3 : Mean Analysis - Effects of Traffic Congestion on the Society

\begin{tabular}{|c|c|c|}
\hline Variable being analysed & $\mathbf{N}$ & Mean \\
\hline $\begin{array}{l}\text { Fuel Consumption } \\
\text { Air Quality Affected } \\
\text { Late Delivery of Goods } \\
\text { Accidents } \\
\text { Passage of Emergency Vehicles Obstructed }\end{array}$ & $\begin{array}{l}208 \\
208 \\
208 \\
208 \\
208\end{array}$ & $\begin{array}{l}1.41 \\
1.82 \\
2.64 \\
2.51 \\
2.92\end{array}$ \\
\hline
\end{tabular}

Questions on effects of traffic congestion on the society on the questionnaire survey were set based on a Likert Scale(see Table 7.3), whereby a mean value of 1 represents strongly agree whilst a mean value of 5 represents strongly disagree. From table 4, mean values of 2.64, 2.51, and 2.92 representing Late delivery, Accidents, and Passage of emergence vehicles obstructed, respectively indicate that respondents partly agree that traffic congestion produces these results to the community or society. On the contrary mean values of 1.41 and 1.82 for Fuel consumption and Air quality affected shows that respondents on average strongly agree that traffic congestion has a negative effect on fuel consumptions of vehicles and air quality in the immediate environment. Table 7.4: Mean Analysis - Effects of Traffic Congestion on the Economy

\begin{tabular}{|c|c|c|}
\hline Variable being analysed & $\mathrm{N}$ & Mean \\
\hline $\begin{array}{l}\text { Late Arrival for work } \\
\text { Poor Employee Performance } \\
\text { Reduced no. of Productive Hours } \\
\text { Economic Growth Obstructed }\end{array}$ & $\begin{array}{l}100 \\
100 \\
100 \\
100\end{array}$ & $\begin{array}{l}1.39 \\
1.68 \\
2.00 \\
2.56\end{array}$ \\
\hline
\end{tabular}

Questions on effects of traffic congestion on the economy were also set based on a Likert Scale (see Table 7.4), whereby a mean value of 1 represents strongly agree whilst a mean value of 5 represents strongly disagree. Respondents depicted that the major effects of congestion to the economy are employees arriving late at work and poor performance of the employees after having arrived late for duty. This is represented by mean figures of 1.39 and 1.68 for late arrival for work and poor employee performance respectively. 
Table 7.5: Mean Analysis - Effects of Traffic Congestion on the Individual

\begin{tabular}{|c|c|c|}
\hline & $\mathrm{N}$ & Mean \\
\hline Safety of Commuters Affected & 100 & 2.21 \\
\hline Stress & 100 & 1.75 \\
\hline Health Problems & 100 & 1.99 \\
\hline Frustration and road rage & 100 & 1.97 \\
\hline Social Life Affected & 100 & 2.22 \\
\hline
\end{tabular}

Questions on effects of traffic congestion on individuals were set based on a Likert Scale ( see Table 7.5), whereby a mean value of 1 represents strongly agree whilst a mean value of 5 represents strongly disagree .As per information in Table 6, stress, frustration and road rage as well as healthy problems where the notable major effects of congestion to individual people represented by 1.75, 1.99 and 197 for Stress, Healthy problems and Frustration and road rage respectively .Respondents also on average partly agree that congestion affects the safety of commuters and individual people's social life.

\section{Discussion}

Traffic congestion is a global nagging phenomenon confronting cities (Mbara,2015). This could be current and non-current traffic congestion (Andoh, 2014). However, current traffic congestion is found in CBDs as it occurs at a particular place, time and daily. This is generally the consequence of factors that act regularly on the transportation system such as daily commuting to work, shop, school or sell. These are users that experience the traffic congestion on daily commuting.

Rapid increases in car ownership in addition to poor land use planning, inadequate road space, lack of regulated parking systems, bad attitude of pedestrians, and motorists cause traffic congestions globally ( Kiunsi, 2013). In Gaborone, the causes of traffic congestion are poor road networks, poor transport planning and an influx of single occupancy vehicles which surpasses the capacity of the existing road networks.

Managing traffic congestion in Gaborone calls for a multi-faceted approach with the following recommendations applicable:

- Improvement/provision of pedestrian walkway

- Introducing urban transit vehicles within the CBD and design outskirt parking

- $\quad$ Retraining/enforcement of personnel to handle the traffic problems

- $\quad$ Provision of parking lots

- Continuous education on the effects of traffic congestion.

- $\quad$ Lane management or/and vehicular flow through traffic management

\section{Conclusion}

Far from having reached its apex, assessing the repercussions of traffic congestion still needs more research and practice. There is strong empirical evidence in this paper demonstrating that people do believe that traffic congestion negatively affects different aspects of a society, economy and an individual. This is where the government as well as other policy makers' roles become vital. The empirical findings can be useful for policy makers, urban and transport planners, individual private vehicle owners, academics, mass transit transport owners and the general public to re-orient their strategies and habits, and opt for an approach that is in the best interest of reducing urban traffic congestion in Gaborone.

\section{Overall Limitations of the Research and Further Research}

The paper has some potential limitations, use of a larger sample size could have been chosen. Results might be biased due to unforeseen circumstances. Furthermore, the lack of qualitative analysis could have resulted in various aspects not being considered.

Directions for Further research can be carried out to develop a broader conceptual framework to assess the impacts of traffic congestion on the society, the economy and the individual, as well as on various other aspects with more explicit results. Additionally, the operational performance, such as the quality, flexibility of service, dependability, speed, and cost, of the public transport can be assessed. Future researchers can also conduct a study on the causes of traffic congestion. Using the study on the impacts of traffic congestion, additional research could be extended toward assessing the different ways in which traffic congestion can be mitigated in Botswana through engagement of alternative modes of transportation.

\section{References}

Abane, A. M. (1993). Tackling traffic congestion in Accra, Ghana: A road user's perspective. Journal of Advanced Transportation, 27(2), 193-206.

Abane, A. M. (2011). Travel behavior in Ghana: Empirical observations from four metropolitan areas. Journal of 
Transport Geography, 19(1), 313-322.

Andoh, A. K. (2014). Managing road traffic congestion in the Cape coast metropolis, Ghana (Masters dissertation). university of cape coast.

Bashingi, N. (2020) 'ScienceDirect ScienceDirect in a changing world The state of congestion in the developing world ; The case of Gaborone ', Transportation Research Procedia. Elsevier B.V., 45(2019), pp. 434-442. doi: $10.1016 /$ j.trpro.2020.03.036.

Currie, J., \& Walker, R. (2011). Traffic congestion and infant health: Evidence from E-Z Pass. American Economic Journal: Applied Economics, 3(1), 65-90.

Dorsamy, C., Puchooa, C., 2013. Alleviating Traffic Congestion Along The M1 Corridor: An Economic Perspective. The Journal of the Institution of Engineers Mauritius [Online]. Available at: http://www.iemauritius.com/upload/files/traffic_congestion_m1_(dorsamy- puchooa).pdf [Accessed 01 April 2020]

Downie (2008). The world worst traffic jams time. (Retrieved on 02nd November 2019) Available at. 〈http://www.time/world/article/0,8599,1733872.html〉.

Essandoh, P. K., \& Armah, F. A. (2011). Determination of ambient noise levels in the main commercial area of Cape Coast, Ghana. Research Journal of Environmental and Earth Sciences, 3(6), 637-644.

Kiunsi, R. B. (2013). A review of traffic congestion in Dar es Salaam city from the physical planning perspective. Journal of Sustainable Development, 6(2), 94.

Maji, S. (2017) 'Traffic Congestion And Possible Solutions A CASE STUDY OF ASANSOL * Sougata Maji', $5(9)$, pp. 42-46.

Mahendra, A. (2009). Vehicle restrictions in four Latin American cities: Is congestion pricing possible? Transport Review, 28, 105-133.

Mensah, J., Annan, J., \& Baidoo, F. (2014). Assessing the impact of vehicular traffic on energy demand in the Accra Metropolis. Journal of Management Policy and Practice, 15(4), 127.

Mbara T,C (2015) Achieving Sustainable Urban Transport in Harare, Zimbabwe: What are the Requirements to Reach the Milestone? University of Johannesburg,, Journal of Transport and Supply Chain Management.

Ndakhona, B. (2020) 'ScienceDirect ScienceDirect in a changing world The state of congestion in the developing world ; The case of Gaborone ', Transportation Research Procedia. Elsevier B.V., 45(2019), pp. 434-442. doi: 10.1016/j.trpro.2020.03.036.

Rahane, S. K., \& Saharkar, U. R. (2014). Traffic congestion-causes and solutions: A study of Talegaon Dabhade city. Journal of Information, Knowledge and Research in Civil Engineering, 3(1), 160-163.

Rodrigue, J. P., Comtois, C., \& Slack, B. (2020). The geography of transportation system. New York: Routledge.

Statistics Botswana (2019) 'Transport \& Infrastructure Stats Brief Quarter 3, 2019', pp. 1-46.

Texas Transportation Institute (TTI) (2011). The keys to estimating mobility in urban areas: Applying definitions and measures that everybody understands. Texas: Texas Transportation Institute.

Victoria Transport Policy Institute (2009). Transportation cost and benefit analysis: Techniques. Victoria, BC, Canada: Estimates and Implications.

Yildirim, M. B. (2001). Congestion toll pricing models and methods for variable demand networks (Doctoral dissertation). University of Florida.

ZHANG, W., 2011. Managing Traffic Congestion Case Study of Hangzhou. European Spatial Planning and Regional Development, Blekinge Institute of Technology.

Bashingi, N. (2020) 'ScienceDirect ScienceDirect in a changing world The state of congestion in the developing world; The case of The state of congestion in the developing Gaborone , Botswana world; The case of Gaborone ', Transportation Research Procedia. Elsevier B.V., 45(2019), pp. 434-442. doi: 10.1016/j.trpro.2020.03.036.

Maji, S. (2017) 'Traffic Congestion And Possible Solutions A CASE STUDY OF ASANSOL * Sougata Maji', 5(9), pp. 42-46.

Statistics Botswana (2019) 'Transport \& Infrastructure Stats Brief Quarter 3, 2019’, pp. 1-46. 